\title{
Green Ocean Strategy: Democratizing Business Knowledge for Sustainable Growth.
}

\author{
Evangelos Markopoulos ${ }^{1}$, Ines Selma Kirane ${ }^{1}$, Clarissa Piper ${ }^{1}$, Hannu Vanharanta ${ }^{2}$ \\ ${ }^{1}$ HULT International Business School, Hult House East, 35 Commercial Rd, E1 1LD, London, \\ United Kingdom \\ ${ }^{2}$ University of Vaasa, School of Technology and Innovations, Wolffintie 34, 65200 Vaasa, \\ Finnland \\ evangelos.markopoulos@faculty.hult.edu,kinesselma01@gmail.com, \\ clarissa.piper@gmail.com, hannu@vanharanta.fi
}

\begin{abstract}
Sustainability should neither be dystopian, nor utopian, but better protopian. To achieve this, thinking green for the common good and benefit for all from all, does not only require thinking smart or green but also thinking together. This paper attempts to define a new set of organizational processes needed for a company to reach a continuous innovative and sustainable strategy by utilizing primarily its own human intellectual capital in an unbiased and democratic way. Such an approach can transmit an organization into a new management typology and leadership that can be defined as a Green Ocean strategy. The paper introduces the Green Ocean Strategy concept via a business transformation framework that can lead an organization from the Red to the Blue and from the Blue to the Green Oceans strategies. The framework is supported by phases, stages, processes, preconditions, and postconditions towards its effective adaptation.
\end{abstract}

Keywords: Strategy · Leadership - Knowledge - Management - Democracy · Transformation · Innovation · Green Ocean · Blue Ocean · Red Ocean.

\section{Introduction}

Today's business environment undergoes a general market uniformization led by globalization. The ever-increasing information providence for environmental, economic and social sustainability and growth has brought organizations and customers to a more responsible and ethical business operations and product consumption. Business environment forces and markets are shifting competition globally towards sustainability, aiming to achieve higher degrees of innovation that can meet the societal, corporate and customer needs and expectations. Sustainability should frame equitable, viable and livable corporate activities and deliverables, while growth should target adding shared value to all stakeholders involved.

Since change is endemic and inevitable, every sustainable shift that can be transmitted to any stakeholder companies deal with, exponentially enhances each achievement previously performed. Such changes impact Blue Oceans from the creation of uncontested markets [1] towards Green Oceans that can foresee and achieve the creation of 
sustainable market spaces for short, middle, and long-term profitability. As Blue Ocean Strategies seek to make competitors irrelevant by creating new customer value, Green Ocean Strategies can refine companies' mission and vision to compound sustainability over existing and profitable performances for a more adequate customer value creation.

Green Oceans Strategies can be seen as the logical, or natural, extension of Blue Ocean Strategies for companies aiming to reach and maintain their performance overtime, while being aligned with today's major social challenges. This can be achieved through the conversion strategies that take place in the 'turquoise canal', the transition passage from Blue to Green Oceans, in a journey that adapts democratic management practices for social, sustainable and shared value innovations.

Enacting a democratic management and leadership perspective in companies' operations management allow Specific, Measurable, Active, Realistic, and Time-bound (SMART) extroversion for internationalization in a globalized environment. The Company Democracy Model [2], [3], can be used and adjusted to form the base framework for driving an organization through the turquoise canal towards Green Oceans. The overall philosophy of the model is based on the principles of organizational sustainability driven by ethical values in a knowledge shared co-evolutionally y-type management and growth culture between the people, the organization and the society.

\section{Towards Social Innovation}

As business environments evolved through multiple disruptive waves over the past few centuries, management discipline turned into management science over the advancements in methods, tools and technologies evolved to manage volume, complexity, operations and above all the fast-changing innovations.

Management methods often rely on classical innovation, which comprises the process of finding new and more efficient solutions in the form of products, services or strategies. Such innovations can benefit directly and indirectly the stakeholders, but the concept has been evolved towards a wider and more social meaning.

Today companies direct their development strategies to create solutions that can solve social or environmental challenges whilst creating social value. This often requires the cooperation of different stakeholders, like businesses, governments, NGOs and individuals at various levels of engagement [4]. Social innovation extends to shared value innovation which derives from the collaborative (open) management ideology that values employees' potential to collaborate at any point of any initiative, though knowledge management for long term value creation [5] The latest form of innovation, referred to as sustainable innovation, is a convergence of green and clean processes which start from the company's leadership, culture \& capabilities and emerge in the new products or services portfolios [6]. Innovation in general becomes more demanding, not necessarily on the product's or service's functionality or performance, but more on the social impact the company must create through its business activities. In the same sense, sustainability is defined with social factors but more than that with the utilization of environmentally friendly resources for higher profitability and long lasting operations.

The evolution of innovation tends to be a race on efficiency and sustainability mostly from the financial dimension. As the world gets interconnected at a tremendous pace, 
innovation extends its definition to cover as many dimensions and target groups it can possible touch. Therefore, the evolution of the classical innovation to the integration of the social, shared value and environmental dimensions define the desired sustainability needed to assure wide applicability, fast return on investment and of course strong competitive advantage.

\section{The Wide Innovation}

The evolution of the traditional innovation, also referred as closed innovation, to the open innovation on thinking outside the box, can be extended to the wide innovation concept characterized by innovation sustainability through its wide application. The width on such innovations varies from the utilization of the intellectual capital as the green fuel for their devolvement on achieving high and fast returns on investments with extensive sustainability.

Closed innovation is internally focused to the organizational boundaries and goals whereas open innovation includes externally focused elements in the organization's innovation model that can generate new products or explore new markets [7]. Wide innovation on the other hand extends the open innovation concept by targeting, and not only exploring new markets. Through rigorous innovation selection organizations move from research to development based on their sustainability strategy.

Open innovation can be related to the blue ocean strategy where new ideas explore new markets and extend to the green ocean where the effectiveness of the blue ocean success is sustained through a green user/client base (Fig. 1).

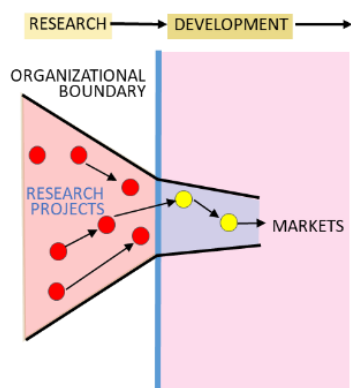

CLOSED INNOVATION

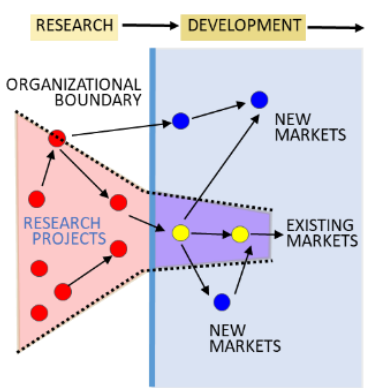

OPEN INNOVATION

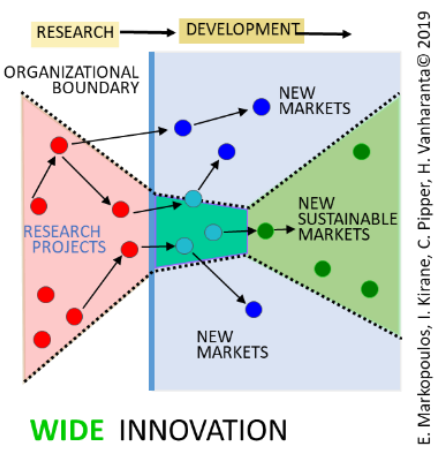

WIDE INNOVATION

Fig. 1. Closed to Wide Innovation evolution.

Further characteristics of the wide innovation is that investments target ideas that require intellectual capital to generate web-based products and services that can bring shared value to the organization and the society by maximizing their target groups. High intellectual capital resources assure innovation maturity and technical quality while the web based innovations reduce production costs, logistics, transportation and are most economical and environmentally friendly. The environmental impact of software development, distribution and usage, especially over the web, is absolutely zero. Software products and services ideally define sustainable and green development. 


\section{The 3S Wide Innovation Matrix.}

The wide innovation elements provide innovation sustainability through social and shared value based on three human intellectual capital utilization dimensions which are the organizational inner change, and the organizational micro and macro environment influence. This triptych creates the $3 \mathrm{~S}$ Wide Innovation Matrix.

The matrix combines the wide innovation elements with the utilization dimensions, creating an area of activity with nine cells. Each cell has a value of completeness and a value of importance. The completeness reflects the degree of fulfillment on the cell's target activities, while the degree of importance indicates the alignment of the cell with the corporate sustainability strategy. The depth and detail of both the target activities and the degree of criticality are set by each organization in particular based on the sustainable innovation strategy selected to execute. Figure 2 presents the Wide Innovation 3S Matrix with indicative values on the completeness and criticality factors. The maximum score an organization can obtain is 100 on each factor.

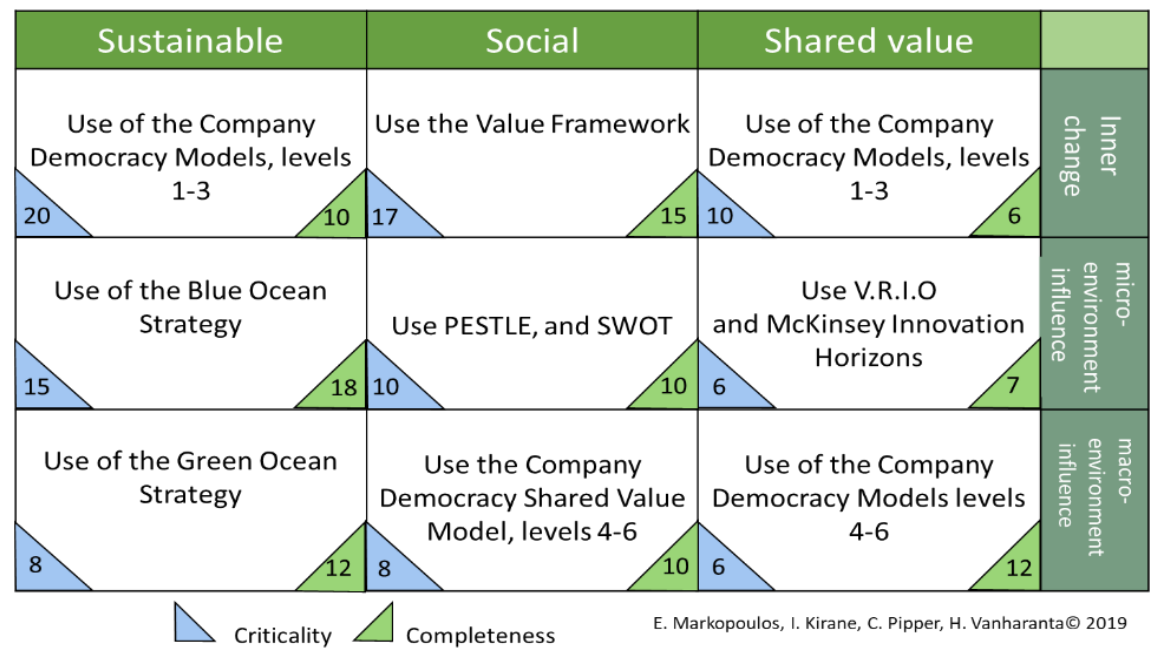

Fig. 2. The 3S Wide Innovation Matrix

Emphasis is given on the criticality dimension of the matrix. It is the degree of completion of the critical elements that directs the efforts on the organizations to reach high effectiveness and success. Each matrix element is represented with the vector WIe (Wide Innovation element) and the values of completeness (i) and criticality (j). (1)

$$
\mathrm{WIe}=(i, j)
$$

Every element has its score which is completeness against criticality (WIeS). (2)

$$
\mathrm{WIeS}=(i / j), \text { where } j \neq 0
$$

The Wide Innovation score (WIS) an organization can achieve is calculated with the WIS formula. (3) 


$$
\mathrm{WIS}=\sum_{i=1}^{9} i / \sum_{j=1}^{9} j, \text { where } J \neq 0
$$

Wide Innovation initiatives with total score 1 are considered perfect in terms of goal settings and performance, while scores under 1 indicate incompleteness. However total scores over 1 indicate incomplete criticality targets. The total criticality of an initiative must be 100 spread over the matrix elements. It must be noted that the criticality values are subjective and set by the organization.

\section{Green Ocean Strategy. Going beyond Blue Ocean.}

Companies so far have been focusing on innovation to lead the competition while staying in it, or leave the competition by creating new markets. The existing Red Ocean Strategy is characterized by high competitiveness in an existing market, where boundaries are defined and accepted. The business' objective is to outperform their competitors and gain a greater market share. However, as the market gets overcrowded, potential growth gets restricted, prospects for profits decrease, and innovation targets short term goals, enough to give a temporary competitive advantage.

Diametrically opposed, the Blue Ocean describes a strategy which creates a new and uncontested marketspace. Blue ocean is led by open innovation initiatives to create and capture new demand making competition irrelevant [8]. Both strategies can be considered costly in resources and infrastructure in their attempt to create long term and profitable results. Emphasis is given on tangible results and on the market trends, while decisions are casement or management driven in each case. Both approaches are led by business development strategies either for short term in a saturated, red, market or long term in an uncontested, blue, market regardless the cost and effort needed.

These two extreme cases create room for a third strategy to be created that can work as an evolution of the Blue Ocean by maintain the Blue characteristics and build on them with human intellectual capital for sustainable and economic innovations mainly for the society, which is the actual market, and not the market as such.

As knowledge constantly flows within the organization, Green innovation via knowledge democratization can generate more challenging, rewarding, cost effective long-lasting opportunities. Democratic green innovation leads to Green Oceans where sustainability is neither dystopian nor utopian, but protopian. It encourages knowledgebased innovation through democratic cultures for collaborative thinking leading to profitable and sustainable innovation. By capturing and shifting the demand to new and social driven market spaces, the Green Ocean Strategy allows companies to turn their proactiveness into long-term competitiveness and sustainably. The Green Ocean Strategy is achieved via brain-driven, technology-oriented social innovations (Fig. 3).

\section{The road map from Red Ocean to Green Ocean.}

Each of the three oceans can be considered as different market domain. The transition from one to the other can be done with an organizational transformation journey 
through process canals that create the infrastructure for such a transition, but also the organizational maturity to handle the market challenges and competition.

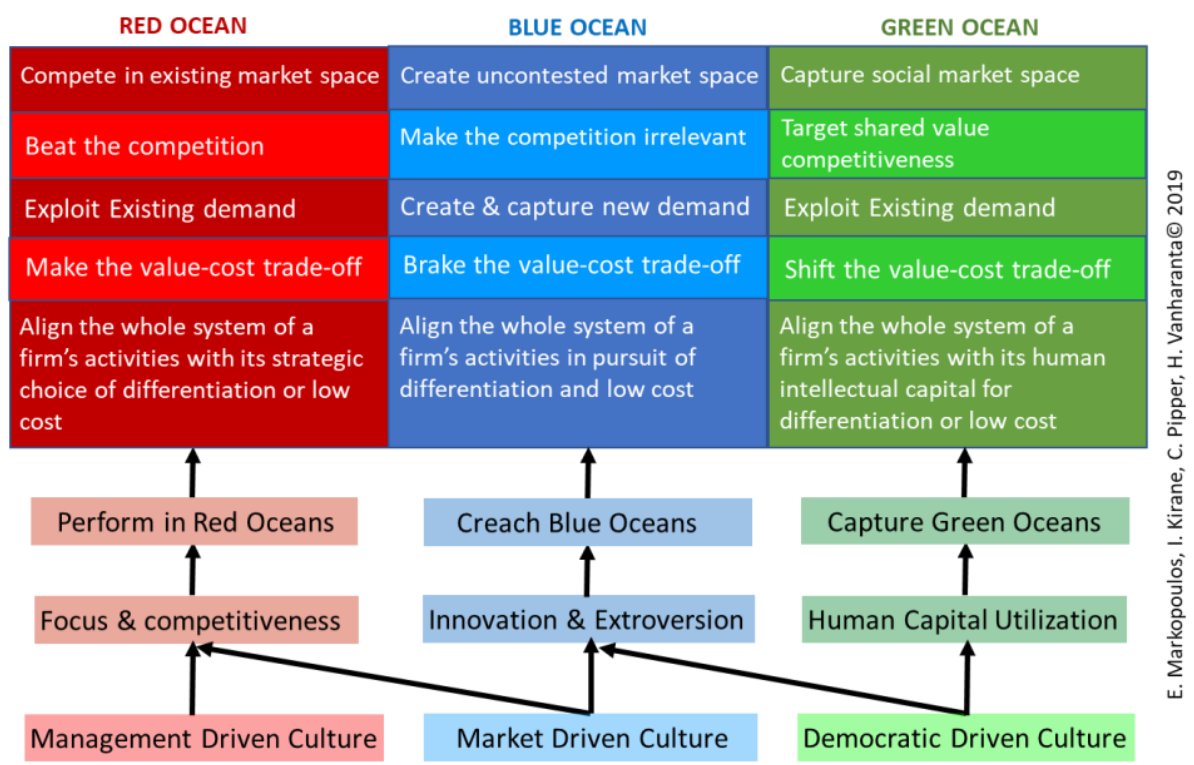

Fig. 3. Ocean strategies evolution and relationships

Companies competing in Red Oceans and seek transition to a Blue Ocean, need to shift their strategies and operations through the Purple Canal in order to reach a Blue Ocean. By using strategic management tools such as SWOT, PESTEL, VRIO, BCM and others, companies can find opportunities to enter an uncontested market which match their core competencies. Furthermore they can attempt to democratize their company structure and knowledge flow and undergo through operational changes that can ignite faster innovation and thereby differentiate from their competition through new markets creation by reaching Blue Oceans.

However Blue Oceans are not the end of the journey. Organizations willing the build on their existing activities and move towards more sustainable strategies must go through the Turquoise Canal to reach a Green Ocean. To analyze the transition strategies for this challenge and to select the proper strategy to go through this canal, companies can use the Wide Innovation 3S Matrix and the Company Democracy Model for effective identification, utilization and capitalization of their human intellectual capital.

This transformation is achieved with democratic generation in a knowledge-based culture for innovation where companies can adequately respond to the shifting demand of consumers within a given industry. This culture builds the self-awareness, self-questioning, self-improvement, and self-actualization operations through which managers can bring companies to the desired market responsiveness level needed to mirror contemporary changes in surrounding environments. Figure 4 presents the two organizational transformation canals towards green oceans. 


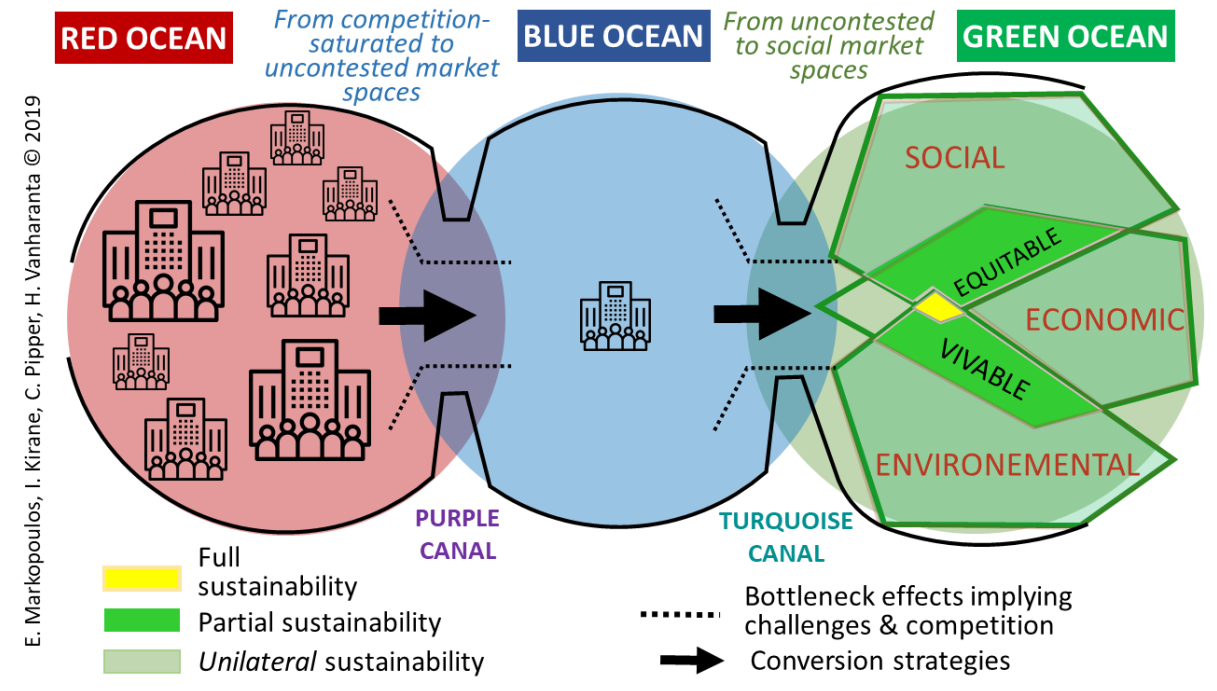

Fig. 4. The oceans transition process through the transformation canals.

\section{Democratization of knowledge for Green Ocean Strategy}

The Green fuel required for an organization to reach Green Oceans through the turquoise canal is an everlasting resource that exists in every organization regardless its size, market or expertise. It is the knowledge of the employees which resides with an organization at no cost, enough to lead a green transformation. However the challenge is on the effective way of collecting, analyzing and utilizing such knowledge. Knowledge democratization is an approach to this challenge. No one knows where an idea can come from or what solutions can derive from the organization's human resources by treating employees as capital assets and not as white- or blue-collar workers.

By changing from within the corporate perspective of business actions, managers can aspire to drive their teams towards the green goals. Enacting the Company Democracy Model (CDM) for innovation creation and management, and by actively engaging the society, companies can successfully implement their conversion strategies in the Turquoise Canal.

The Company Democracy Model provides the actions to be performed in order to identify the extent of company democracy, based on the individual and collective evolution dimensions. The model adapts the ancient Hellenic wisdom from and the Delphic Maxims 'Know Thyself', 'Miden Agan' and 'Metron Ariston' [9] in a business context to build a co-evolutionary process framework. It is also aligned with the Co-Evolute methodology for innovation from internal corporate knowledge generation [10].

The classification of the knowledge is done through the use of ontologies to dynamically capture its creation, evolution, and behavior based on the employee's capability, maturity, competence and capacity [11]. This continuous approach turns organizational knowledge from tacit into explicit and generates the fuel for the organizations to move from Red Oceans to Blue Oceans [12]. 
The adaptation of the Company Democracy Model into Green Ocean Strategy framework maintains the six levels of the original model used to drive organizations from the Red to the Blue Oceans under a new philosophy based on knowledge screening for green and sustainable innovations and corporate strategies (Fig. 5).

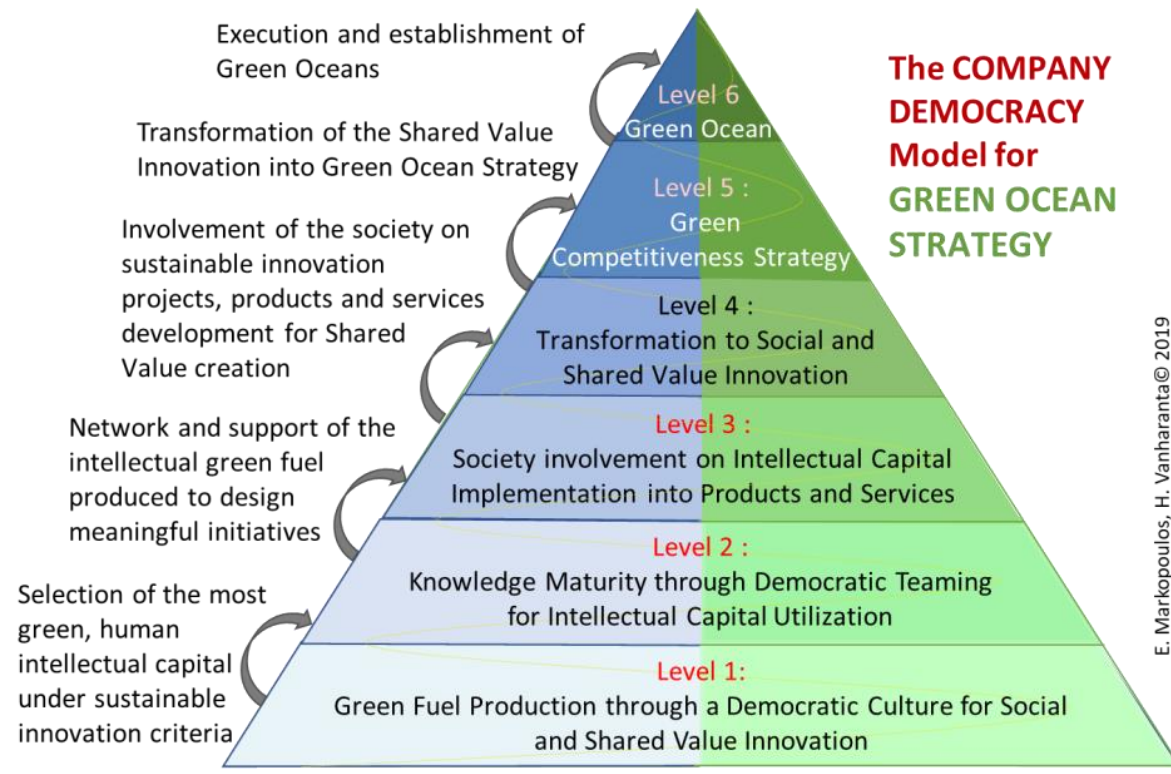

Fig. 5. Knowledge evolution for Green Oceans via the Company Democracy Model

In the model, companies evolve in a pyramid through an incremental progression. Starting from a retrospective/introspective phase, managers use democratic teaming processes to acquire the self-awareness needed to democratically re-organize their actions [13]. Companies move up the levels by expanding their democratic philosophy in their organization's structure and business actions.

\section{A co-evolutionary Spiralmid for sustainable innovations}

The Company Democracy Model for Green Ocean creation is co-evolutionary based innovation management framework. The model is executed via a spiral process in which organizations create, share and utilize integrated knowledge from the society and its human resources (Fig. 6).

The first level of the model creates a democratic culture through which knowledge is generated and screened for sustainability and wide innovation characteristics. It is the stage where the 3S Matrix assess the quality of the knowledge for its transformation into green intellectual capital fuel to grow sustainable strategies and innovations. 


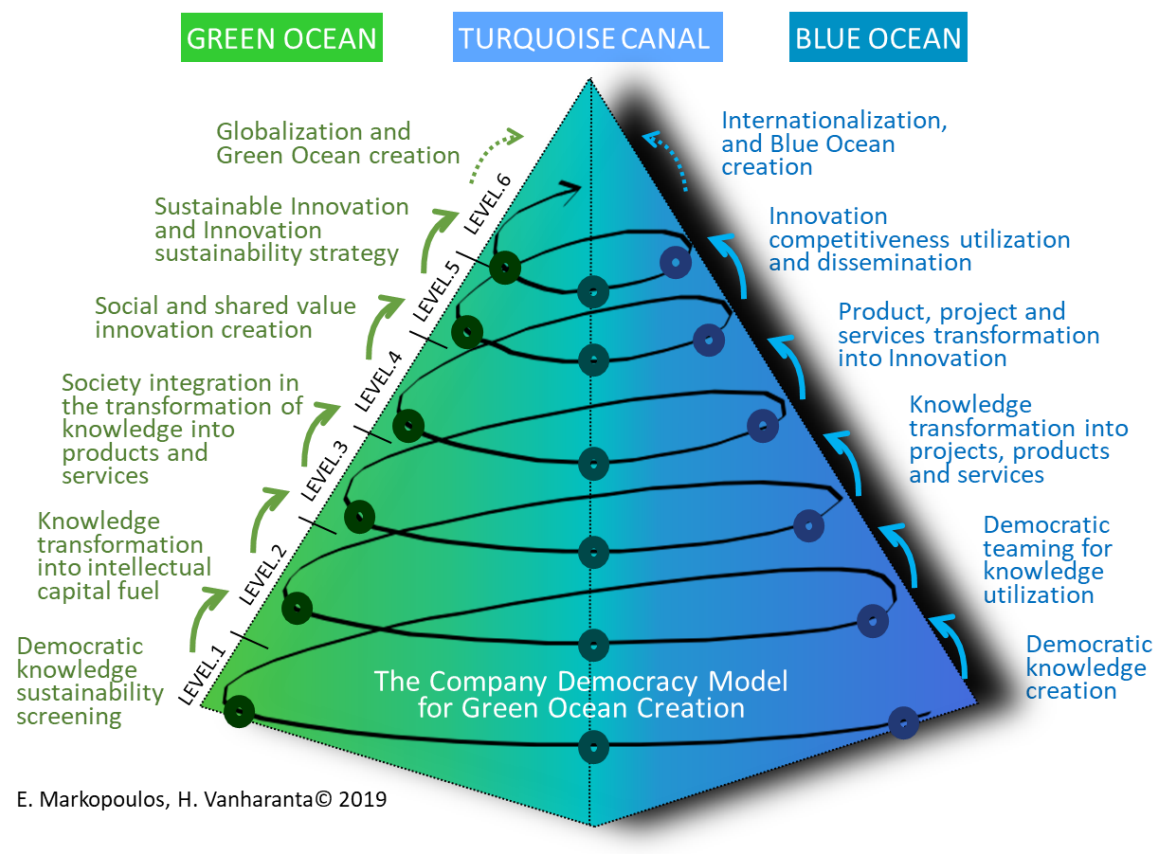

Fig. 6. Co-evolutionary spiral for dynamic sustainability \& innovation management

On level two, the model supports the green thinkers of level 1 with the resources needed to validate their knowledge and transform it into practical products and projects designs. Level three integrates the society in the transformation of the green prototypes into actual products and services which are been tested, enhanced and evolved with the society needs, concerns and expectations.

The fourth level and based on the effectives of the deliverables of level three, and turns the social innovation into shared value innovation from which the benefits can be more direct and profitable to both the society and the economy. Level five utilizes the success of the previous levels by designing and executing an organizational innovation sustainability strategy that assures long lasting benefits and global awareness. Lastly level six is where Green oceans are identified based on the effectives of level five.

The global adaptation of sustainable innovation created from the organizational human intellectual capital and the society, is the epitome of the green ocean journey. Blue and Green oceans run in a symbiotic mode as the innovation of the Blue extents to the sustainability of the Green. However Green oceans can be reached without necessarily stopping in a Blue Ocean but by utilizing the innovation philosophy of the Blue directly into the Green innovation approach. 


\section{Conclusions}

Knowledge can be the most valuable resource organizations have, however identifying this knowledge and utilizing it properly turns out to be quite a Herculian challenge. It is not the absence of knowledge from the organization's human recourses but mostly the lack on an appropriate democratic culture that can transform this valuable resource into clean, intellectual, fuel for organizational strategy development. Moving from data and information driven strategies to knowledge driven strategies and from open innovation to sustainable innovation requires qualitative and quantitative human intellectual capital. Blue oceans provide unique opportunities for growth and development which often requires the relative financial capital and time investments.

However Green Oceans can be reached under the Blue Ocean thinking and process with less financial capital investments and market uncertainty risks. The utilization of intellectual capital instead of monetary capital and the integration of the society instead of the trends is what differentiates the two approaches. The company democracy model and the transition journey through the turquoise canal can contribute on turning Blue Oceans to Green Oceans under a Y-theory shared value democratic management philosophy.

\section{References}

1. Kim W. C., Mauborgne R.: Blue ocean strategy :how to create uncontested market space and make the competition irrelevant Boston, Mass. Harvard Business School Press (2005)

2. Markopoulos E., Vanharanta H.: Democratic Culture Paradigm for Organizational Management and Leadership Strategies - The Company Democracy Model. Proceedings of the 5th International Conference on Applied Human Factors and Ergonomics AHFE 2014 (2014).

3. Vanharanta H., Markopoulos E.: Creating a Dynamic Democratic Company Culture for Leadership, Innovation, and Competitiveness. 3rd Hellenic-Russian Forum. Sept.17. (2013).

4. World Economic Forum. http://www3.weforum.org/docs/WEF_Social_Innovation_Guide.pdf

5. Markopoulos E., Vanharanta. H.: The Company Democracy Model for the Development of Intellectual Human Capitalism for Shared Value, Procedia Manufacturing, vol 3, pp 603-610 (2015)

6. Harvard Business Review. https://hbr.org/2007/10/harvard-business-ideacast-64-s

7. W. Krause, C. Schutte and N. du Preez 'Open Innovation in South African small and medium-sized enterprises. 42, Proceedings, 15-18 July 2012, Cape Town, South Africa. (2012)

8. Kim W. C., Mauborgne R.: Value innovation: a leap into the blue ocean, Journal of Business Strategy, vol. 26 Issue: 4, pp.22--28 (2005)

9. Parke H., Wormell D.: The Delphic Oracle, Basil Blackwell, vol. 1, pp 389 (1956).

10. Kantola, J., Vanharanta, H., Karwowski, W.: The Evolute System: A Co-Evolutionary Human Resource Development Methodology. In the International Encyclopedia of Ergonomics and Human Factors. Karwowski, W., CRC Press. (2006).

11. Paajanen, P., Piirto, A., Kantola, J., Vanharanta, H.: FOLIUM - Ontology for Organizational Knowledge Creation. 10th World multi-conference on systemics, cybernetics, and informatics. (2006).

12. Nonaka I., Takeuchi H., The Knowledge-Creating Company: How Japanese Companies Create the Dynamics of Innovation, New York, Oxford University Press (1995).

13. Markopoulos E., Vanharanta H.: Project teaming in a democratic company context, Theoretical Issues in Ergonomics Science, vol. 19:6, pp 673--691 (2018) 